\title{
Subendocardial ischaemia in patients with discrete subvalvar aortic stenosis ${ }^{1}$
}

\author{
G. A. CASSEL, J. D. BENJAMIN, AND J. B. LAKIER \\ From the Department of Medicine, University of the Witwatersrand, and the Cardiac Clinic, \\ General Hospital, fohannesburg, South Africa
}

SUMMARY The evidence for subendocardial ischaemia was studied in 12 patients with discrete subvalvar aortic stenosis. Symptomatology, electrocardiographic criteria, and pressure difference across the left ventricular outflow tract were compared with the subendocardial flow index ( $\left.\frac{\text { diastolic pressure time index }}{\text { systolic pressure time index }}\right)$. All symptomatic patients had a large pressure difference and abnormal index, but 4 asymptomatic patients had pressure differences greater than $60 \mathrm{mmHg}$ and a low index. One of these 4 patients had a normal resting electrocardiogram. In patients with borderline accepted indications for surgery, calculation of the subendocardial flow index may be an additional useful variable in the timing of surgery.

Valvar and subvalvar aortic stenosis are common congenital heart lesions. Discrete subvalvar stenosis accounts for approximately 20 per cent of these cases (Braunwald et al., 1963; Campbell, 1968; Kelly et al., 1972; Mody and Mody, 1975), and is thought to be caused by incomplete degeneration of the bulbus cordis in the region of the left ventricular outflow tract (Keith, 1924). Patients frequently have very high left ventricular systolic pressures and may have features on the electrocardiogram compatible with subendocardial ischaemia.

The occurrence of subendocardial ischaemia in experimental left ventricular outflow tract obstruction (Brazier et al., 1974) and in children with valvar aortic stenosis (Lakier et al., 1974; Lewis et al., 1974; Krovetz and Kurlinski, 1976), has been studied from data obtained both at cardiac catheterisation and from myocardial cell histology. It was the purpose of this study to analyse retrospectively the data of patients at this clinic with discrete subvalvar aortic stenosis and to assess the degree of subendocardial ischaemia.

\section{Subjects and methods}

The study included 12 patients with discrete

1 Supported in part by a grant from the South African Medical Research Council.

Received for publication 5 August 1977 subvalvar aortic stenosis who presented to the Cardiac Unit of the Johannesburg Hospital between 1971 and 1976. All patients were assessed clinically and were then subjected to cardiac catheterisation.

Cardiac catheterisation was performed under local anaesthesia. Mild sedation and analgesics were administered 30 to 60 minutes before the procedure. A percutaneous femoral artery approach was used in all but one patient in whom a right brachial arteriotomy was performed. Pressures were recorded on an Electronics for Medicine DR12 recorder using Statham P23-DB pressure transducers. Pressure differences across the left ventricular outflow tract (LVOT) were measured from simultaneous left ventricular and aortic tracings in 2 patients (when the left ventricle could be entered across a patent foramen ovale) or on withdrawal from the left ventricle to the aorta in the remaining 10 patients. Heart rate was recorded at the same time. Blood was withdrawn from the aorta for estimation of percentage oxygen saturation in 9 patients. The oxygen content (C) was calculated from the formula:

$$
\frac{\% \mathrm{O}_{2} \text { saturation } \times \text { haemoglobin } \times 1.354}{10}
$$

As subendocardial blood flow is almost entirely confined to diastole, it is reflected by the area between the left ventricular and aortic pressure tracings during diastole (diastolic pressure time index or DPTI) (Buckberg et al., 1972a). Left 388 


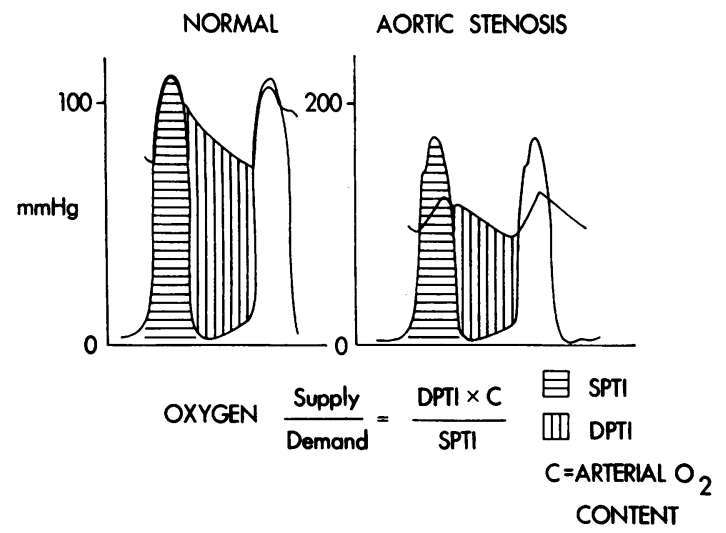

Fig. Superimposed left ventricular and aortic pressures in the normal subjects and in patients with aortic stenosis. Derivation of the subendocardial flow index is shown (for discussion see text).

ventricular myocardial blood flow requirements can be assessed by measuring the area under the left ventricular pressure tracing during systole (systolic pressure time index or SPTI). The supply: demand ratio is, therefore, DPTI/SPTI (Brazier et al., 1974) and has been termed the subendocardial flow index (Krovetz and Kurlinski, 1976). $\frac{\text { DPTI }}{\text { SPTI }}$ was calculated in all 12 of our patients by measuring the respective area on simultaneous or superimposed left ventricular and aortic pressure tracings (Fig.). When left ventricular and aortic pressures were obtained on withdrawal across the left ventricular outflow tract, pressure tracings immediately before and after withdrawal were superimposed and then traced out, matching the pressure tracings with the corresponding identical RR interval on the electrocardiogram to ensure accurate reproduction. DPTI

$\frac{\text { DPTI }}{\text { SPTI }} \times \mathrm{C}$ is a measurement of subendocardial oxygen delivery and not only blood flow (Brazier et al., 1974). It was calculated in 9 patients in whom per cent oxygen saturation had been measured at the time of cardiac catheterisation. Subendocardial

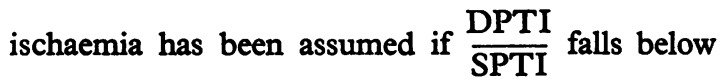
$0 \cdot 7$ (Buckberg et al., 1972b; Brazier et al., 1974) and if $\frac{\text { DPTI }}{\text { SPTI }} \times C$ is below 10 (Brazier et al., 1974).

\section{Results}

PREOPERATIVE CLINICAL ASSESSMENT The relevant clinical data are presented in Table 1.
There were 6 male and 6 female patients, with an age range of 4 to 18 years (mean of 9 years) at the time of investigation.

Seven patients (cases $3,5,6,8,9,10,12$ ) were asymptomatic but a cardiac murmur had been detected during routine examination. Two complained of dizziness (cases 4 and 11) and one had syncopal episodes (case 7). One had recurrent respiratory infection (case 2) and the last patient (case 1) presented in biventricular failure, having been short of breath for one month. The pulse was assessed as normal in as many as 10 of the 12 patients, but was of small volume in one and slow rising in one. A grade 3-4/6 ejection systolic murmur was audible in all and lasted two-thirds of systole or more. The murmur was of maximum intensity at the left parasternal border, but always radiated into the carotid arteries. An associated short soft early diastolic murmur was present in 5 patients. The splitting of the second heart sound was completely reversed in only 3 of the 12 patients. None had an ejection systolic click. Two patients (cases 4 and 9) had normal chest radiographs, whereas in the remaining 10 there was evidence of left ventricular hypertrophy.

Seven of the patients had associated cardiovascular abnormalities (Table 1). Five had coarctation of the aorta; in one (case 11) this had been corrected before the study whereas 3 others (cases 2, 8, and 10) had the coarctation repaired after resection of the subvalvar membrane. The remaining patient (case 6) had mild coarctation demonstrable angiographically only. All other associated abnormalities were mild and were only detected at the time of study. One patient had minimal pulmonary stenosis and another had minimal supravalvar aortic stenosis. Two further patients had small ventricular septal defects on cineangiography which were not haemodynamically significant and consequently did not affect the present investigation. Review of the preoperative electrocardiograms showed the presence of left ventricular hypertrophy on voltage criteria in 10 patients (Alimurung et al., 1951). Six patients had normal ST segments and $T$ waves, whereas the remaining 6 had ST segments and T wave changes compatible with subendocardial ischaemia of varying degree (Table 1). The mean frontal plane QRS axes ranged from $-30^{\circ}$ to $+130^{\circ}$.

At cardiac catheterisation (Table 2), the peak left ventricular pressure ranged from 120 to $275 \mathrm{mmHg}$, but in only one patient (case 10) was the enddiastolic pressure much increased. The pressure difference across the left ventricular outflow tract ranged from $40 \mathrm{mmHg}$ to $166 \mathrm{mmHg}$ and was greater than $60 \mathrm{mmHg}$ in 9 of the 12 patients. The heart rate at the time of study was greater than 100 
Table 1 Clinical signs: relevant clinical data on 12 patients with subvalvar aortic stenosis

\begin{tabular}{|c|c|c|c|c|c|c|}
\hline $\begin{array}{l}\text { Case } \\
\text { No. }\end{array}$ & $\begin{array}{l}\text { Age } \\
(y)\end{array}$ & Sex & Presentation & $\begin{array}{l}\text { Blood pressure } \\
(\mathrm{mmHg})\end{array}$ & Associated abnormalities & $\begin{array}{l}\text { Resting electro- } \\
\text { cardiogram } \\
\text { ('ischaemia') }\end{array}$ \\
\hline 1 & 7 & $\mathbf{M}$ & Biventricular failure & $100 / 75$ & - & - \\
\hline 2 & 5 & $\mathbf{M}$ & Recurrent respiratory infections & $130 / 110$ & $\begin{array}{l}\text { Coarctation of aorta, } \\
\text { pulmonary stenosis }\end{array}$ & 一 \\
\hline 3 & 18 & $\mathbf{M}$ & Routine examination & $130 / 70$ & - & Severe \\
\hline 4 & 14 & $\mathbf{F}$ & Dizziness & $98 / 78$ & - & Moderate \\
\hline 5 & 6 & $\mathbf{M}$ & Routine examination & $90 / 60$ & $\begin{array}{l}\text { Supravalvar aortic stenosis, } \\
\text { ventricular septal defect }\end{array}$ & - \\
\hline 6 & 9 & $\mathbf{F}$ & Routine examination & $110 / 90$ & Coarctation of aorta & - \\
\hline 7 & 7 & $\mathbf{F}$ & Transient blackouts & $100 / 80$ & Ventricular septal defect & Mild \\
\hline 8 & 5 & $\mathbf{M}$ & Routine examination & $120 / 90$ & Coarctation of aorta & - \\
\hline 9 & 6 & $\mathbf{F}$ & Routine examination & $75 / 65$ & - & Moderate \\
\hline 10 & 10 & $\mathbf{F}$ & Routine examination & $135 / 100$ & Coarctation of aorta & Moderate \\
\hline 11 & 17 & $\mathbf{M}$ & Dizziness & $134 / 86$ & Coarctation of aorta & Moderate-severe \\
\hline 12 & 4 & $\mathbf{F}$ & Routine examination & $90 / 60$ & 一 & - \\
\hline
\end{tabular}

Table 2 Cardiac catheterisation data on 12 patients with subvalvar aortic stenosis

\begin{tabular}{|c|c|c|c|c|c|}
\hline $\begin{array}{l}\text { Case } \\
\text { No. }\end{array}$ & $\begin{array}{l}\text { Heart rate } \\
\text { (beat s/min) }\end{array}$ & $\begin{array}{l}L V \text { pressure } \\
(\mathrm{mmHg})\end{array}$ & $\begin{array}{l}\text { Pressure difference } \\
\quad(\mathrm{mmHg})\end{array}$ & $\frac{D P T I}{S P T I}$ & $\frac{D P T I \times C}{S P T I}$ \\
\hline $\begin{array}{r}1 \\
2 \\
3 \\
4 \\
5 \\
6 \\
7 \\
8 \\
9 \\
10 \\
11 \\
12\end{array}$ & $\begin{array}{r}110 \\
100 \\
108 \\
72 \\
100 \\
136 \\
136 \\
85 \\
108 \\
88 \\
88 \\
115\end{array}$ & $\begin{array}{l}240 / 5 \\
275 / 15 \\
220 / 4 \\
180 / 12 \\
158 / 12 \\
215 / 7 \\
200 / 8 \\
170 / 14 \\
180 / 7 \\
175 / 25 \\
205 / 15 \\
120 / 1\end{array}$ & $\begin{array}{r}166 \\
165 \\
105 \\
95 \\
58 \\
75 \\
102 \\
60 \\
98 \\
68 \\
80 \\
40\end{array}$ & $\begin{array}{l}0.28 \\
0.30 \\
0.35 \\
0.36 \\
0.44 \\
0.47 \\
0.51 \\
0.52 \\
0.52 \\
0.59 \\
0.63 \\
0.80\end{array}$ & $\begin{array}{l}4.5 \\
4 \cdot 1 \\
6 \cdot 2 \\
-6 \cdot 1 \\
- \\
6 \cdot 6 \\
6 \cdot 9 \\
9 \cdot 1 \\
\overline{11} \cdot 1 \\
11 \cdot 6\end{array}$ \\
\hline
\end{tabular}

DPTI, diastolic pressure time index; SPTI, systolic pressure time index; C, oxygen content of arterial blood.

beats per minute in 8 of the 12 cases, with a range of 72 to 136 beats per minute.

In all but one patient (case 12) the subendocardial flow index was reduced below $0 \cdot 7$. Where oxygen content was available, the corrected ratio $\frac{\mathrm{DPTI}}{\mathrm{SPTI}}$ $\times$ C showed that only one other patient (case 11) had a ratio greater than 10 . The pressure difference across the left ventricular outflow tract and subendocardial ischaemia as predicted by the subendocardial flow index were compared with the presence of subendocardial ischaemia on the resting electrocardiogram. Nine patients had left ventricular outflow tract pressure differences greater than $60 \mathrm{mmHg}$ and low subendocardial flow indices. Six of these showed evidence of subendocardial ischaemia on the resting electrocardiogram, whereas 3 had normal electrocardiographic tracings. One of the latter patients (case 8) had an effort electrocardiogram and the tracing after effort was also normal. Of the remaining 3 patients in the series, 1 (case 11) had evidence of ischaemia on the resting electrocardio- gram and a left ventricular outflow tract pressure difference of $80 \mathrm{mmHg}$ but the corrected ratio was normal. One patient (case 5) with a left ventricular outflow tract pressure difference of $58 \mathrm{mmHg}$ and a normal electrocardiogram had a low index; the third patient (case 12) had a pressure difference of $40 \mathrm{mmHg}$, with a normal electrocardiogram and subendocardial flow index.

\section{Discussion}

Subvalvar aortic stenosis can be divided into 3 anatomically different types as differentiated from hypertrophic cardiomyopathy (Newfeld et al., 1976). In general, surgery for these categories of subaortic stenosis is associated with a low perioperative mortality (Shariatzadeh et al., 1972). However, residual pressure differences across the left ventricular outflow tract, aortic regurgitation, and damage to the mitral valve complex, particularly in patients with the fibromuscular type, are not uncommon (Kelly et al., 1972). Furthermore, bundle-branch block or complete heart block may supervene at 
operation (Shariatzadeh et al., 1972; Champsaur et al., 1973; Newfeld et al., 1976). Consequently the morbidity associated with operation, especially for fibromuscular subaortic stenosis, is considerable (Kelly et al., 1972; Newfeld et al., 1976).

Campbell (1968) reported a mortality rate of 0.6 per cent per annum in the first two decades in patients with all forms of aortic stenosis. Serial haemodynamic observations in patients with subvalvar aortic stenosis have shown that the lesion is often progressive (Buckberg et al., 1975; Mody and Mody, 1975). Early operation for aortic stenosis has thus been advocated. But the accepted indications for surgery have varied. Recently, Newfeld et al. (1976) suggested that the presence of a pressure difference of $40 \mathrm{mmHg}$ or more across the left ventricular outflow tract and of a discrete membrane was an indication for operation. In our view, the determination of the subendocardial flow index is an additional help in determining the time for operation.

Supply of oxygen to the various regions of the myocardium is determined by the coronary blood flow and the oxygen content of the blood. Subendocardial flow differs from flow in the rest of the myocardium in that it is confined to diastole (Hoffman and Buckberg, 1974). The blood flow can be increased by vasodilatation alone and subsequently also by the coronary driving force and the duration of diastole (Brazier et al., 1974). In the determination of the subendocardial flow index, heart rate is of considerable importance. Important obstruction across the left ventricular outflow tract causes prolongation of the systolic ejection time, with a concomitant decrease in diastolic filling time which would be further shortened by tachycardia. These factors would result in a reduction of subendocardial blood flow. Experimentally, Brazier and Buckberg (1975) showed that when the heart rate was increased in dogs, the left ventricular subendocardial flow fell 35 per cent in those with a fixed level of supravalvar aortic stenosis, whereas flow increased by 51 per cent in controls. In that study, the greater the level of outflow obstruction the greater was the reduction in the duration of diastole. In a study of children with congenital aortic stenosis, Lewis et al. (1974) found that the supply:demand ratios were normal in all cases where the heart rate was below 100 beats per minute; conversely, of those patients with tachycardia, only one had a normal ratio. The valve areas in these 2 subgroups were not significantly different.

For these reasons, all patients with heart rates below 100 beats per minute at the time of study should probably be subjected to isometric hand exercises or atrial pacing to assess both the pressure difference and the subendocardial flow index under conditions of stress. Buckberg et al. (1975) infused isoprenaline into patients with aortic stenosis with a resultant significant decrease in the DPTI and a significant rise in the SPTI. Brazier and Buckberg (1975) noted a similar effect by atrial pacing of dogs with a fixed level of outflow tract obstruction. However, exercise would be more physiological than an infusion of an inotropic agent or pacing. It should be noted that the only patient (case 11) who had a normal ratio when corrected for oxygen content, had a heart rate of only 88 beats per minute at the time of investigation.

Although several variables are used to assess the timing of surgery in patients with left ventricular outflow tract obstruction and its effect on the myocardium, including symptomatology, physical signs, electrocardiographic features, and cardiac catheterisation data, none of these is infallible. Studies have shown an indifferent correlation between symptoms and aortic valve area (El-Said et al., 1972) or peak systolic pressure difference (Hohn et al., 1965) as well as between symptoms, electrocardiographic or radiographic findings, and the systemic pressure difference (Braunwald et al., 1963) or the aortic valve orifice (Friedman et al., 1971; Cohen et al., 1972). Recently, Krovetz and Kurlinski (1976) have found a good correlation between symptomatology and a low subendocardial flow index in patients with valvar aortic stenosis.

Depression of the ST segment and inversion of the $T$ waves on the surface electrocardiogram are regarded as features of subendocardial ischaemia. However, experimental evidence and studies using intracavity electrodes (Scheuer and Brachfeld, 1966; Monroe et al., 1972) have suggested that the changes on a surface electrocardiogram may be a relatively insensitive and late manifestation. The subendocardial flow index in our patients was compared with the resting electrocardiogram, and though 6 patients had evidence of subendocardial ischaemia on the surface electrocardiogram and also had abnormal subendocardial flow indices, 4 patients had low indices with normal electrocardiograms. In the one patient who had an effort stress test it was also normal though there was an abnormally low index at cardiac catheterisation.

All patients in this study who presented with symptoms had an abnormal ratio but the ratio was also grossly abnormal in 5 other patients who were asymptomatic yet had pressure differences across the left ventricular outflow tract of between 58 and $102 \mathrm{mmHg}$. Whereas ischaemic changes on the electrocardiogram and the presence of symptoms are usually indicative of significant outflow tract obstruction, our findings indicate that their absence 
does not exclude this possibility.

The subendocardial flow index is easily measured at cardiac catheterisation and is probably a more sensitive indication of subendocardial ischaemia than conventional electrocardiography. We believe that because of the low operative mortality, especially in patients with membranous subvalvar aortic stenosis, patients with borderline accepted indications for surgery who have a low subendocardial flow index, either at rest or after exercise, should be referred for surgical correction.

The authors thank Professor S. E. Levin and Dr S. Milner for allowing them to study their patients.

\section{References}

Alimurung, M. M., Joseph, L. G., Nadas, A. S., and Massell, B. F. (1951). The unipolar precordial and extremity electrocardiogram in normal infants and children. Circulation, 4, 420-429.

Braunwald, E., Goldblatt, A., Aygen, M. M., Rockoff, S. D., and Morrow, A. G. (1963). Congenital aortic stenosis. I. Clinical and hemodynamic findings in 100 patients. Circulation, 27, 426-450.

Brazier, J. R., and Buckberg, G. D. (1975). Effects of tachycardia on the adequacy of subendocardial oxygen delivery in experimental aortic stenosis. American Heart fournal, 90, 222-230.

Brazier, J., Cooper, N., and Buckberg, G. D. (1974). The adequacy of subendocardial oxygen delivery: the interaction of determinants of flow, arterial oxygen content and myocardial oxygen need. Circulation, 49, 968-977.

Buckberg, G. D., Fixler, D. E., Archie, J. P., and Hoffman, J. I. E. (1972a). Experimental subendocardial ischemia in dogs with normal coronary arteries. Circulation Research, 30, 67-81.

Buckberg, G. D., Towers, B., Paglia, D. E., Mulder, D. G., and Maloney, J. V. (1972b). Subendocardial ischemia after cardiopulmonary bypass. Fournal of Thoracic and Cardiovascular Surgery, 64, 669-684.

Buckberg, G. D., Eber, L., Herman, M., and Gorlin, R. (1975). Ischemia in aortic stenosis: hemodynamic prediction. American fournal of Cardiology, 35, 778-784.

Campbell, M. (1968). The natural history of congenital aortic stenosis. British Heart fournal, 30, 514-526.

Champsaur, G., Trusler, G. A, and Mustard, W. T. (1973). Congenital discrete subvalvar aortic stenosis: surgical experience and long-term follow-up in 20 paediatric patients. British Heart fournal, 35, 443-446.

Cohen, L. S., Friedman, W. F., and Braunwald, E. (1972).
Natural history of mild congenital aortic stenosis elucidated by serial hemodynamic studies. American fournal of Cardiology, 30, 1-5.

El-Said, G., Galioto, F. M., Mullins, C. E., and McNamara, D. G. (1972). Natural hemodynamic history of congenital aortic stenosis in childhood. American fournal of Cardiology, 30, 6-12.

Friedman, W. F., Modlinger, J., and Morgan, J. R. (1971). Serial hemodynamic observations in asymptomatic children with valvar aortic stenosis. Circulation, 43, 91-97.

Hoffman, J. I. E., and Buckberg, G. D. (1974). Regional myocardial ischemia-causes, prediction and prevention. Vascular Surgery, 8, 115-131.

Hohn, A. R., van Praagh, S., Douglas Moore, A. A., Vlad, P., and Lampert, E. C. (1965). Aortic stenosis. Circulation, 31 and 32, Suppl. III, 4-12.

Keith, A. (1924). Fate of the bulbus cordis in the human heart. Lancet, 2, 1267-1272.

Kelly, D. T., Wulfsberg, E., and Rowe, R. D. (1972). Discrete subaortic stenosis. Circulation, 46, 309-322.

Krovetz, L. J., and Kurlinski, J. P. (1976). Subendocardial blood flow in children with congenital aortic stenosis. Circulation, 54, 961-965.

Lakier, J. B., Lewis, A. B., Heymann, M. A., Stanger, P., Hoffman, J. I. E., and Rudolph, A. M. (1974). Isolated aortic stenosis in the neonate: natural history and hemodynamic considerations. Circulation, 50, 801-808.

Lewis, A. B., Heymann, M. A., Stanger, P., Hoffman, J. I. E., and Rudolph, A. M. (1974). Evaluation of subendocardial ischemia in valvar aortic stenosis in children. Circulation, 49, 978-984.

Mody, M. R., and Mody, G. T. (1975). Serial hemodynamic observations in congenital valvular and subvalvular aortic stenosis. American Heart Fournal, 89, 137-143.

Monroe, R. G., Gamble, W. J., LaFarge, C. G., Kumar A. E., Stark, J., Sanders, G. L., Phornphutkul, C., and Davies, M. (1972). The Anrep effect reconsidered. Fournal of Clinical Investigation, 51, 2573-2583.

Newfeld, E. A., Muster, A. J., Paul, M. H., Idriss, F. S., and Riker, W. L. (1976). Discrete subvalvar aortic stenosis in children: study of 51 patients. American fournal of Cardiology, 38, 53-61.

Scheuer, J., and Brachfeld, N. (1966). Coronary insufficiency: relations between hemodynamic, electrical and biochemical parameters. Circulation Research, 18, 178-189.

Shariatzadeh, A. N., King, H., Girod, D., and Shumacker, H. B., Jr. (1972). Discrete subaortic stenosis: a report on 20 cases. Fournal of Thoracic and Cardiovascular Surgery, 63, 258-262.

Requests for reprints to Dr G. A. Cassel, Cardiac Clinic, General Hospital, Johannesburg 2001, South Africa. 